\title{
Big Data Analytics: A New Flavour for Educational Industry
}

\author{
S. K. SathyaHari Prasad ${ }^{1}$, P. Bhavya ${ }^{2}$ and M. Kalpana Devi ${ }^{3}$ \\ ${ }^{1,2}$ PG Student, ${ }^{3}$ Senior Assistant Professor, Department of Master of Computer Applications \\ ${ }^{1,2 \& 3}$ Sreenivasa Institute of Technology and Management Studies, Chittoor, Andhra Pradesh, India \\ E-Mail: sathyahari74.shp@gmail.com, psrbhavya@gmail.com, kalpana_melpadi@yahoo.com
}

\begin{abstract}
Mushrooming of educational institutions in recent times has led to cut throat competition and the success of an institution has become necessary. The technological development has increased the availability of information. Bigdata analytics has made a rapid advancement and gained a huge momentum in recent years, which feeds into the field of academic institutions to better understand the learner's needs and address them appropriately. Hence, it is important to have an understanding of Big Data and its applications in the educational industry. The purpose of this descriptive paper is to provide an overview of Big Data, some of the benefits and challenges of big data in the field of education. Though Big Data can provide big benefits, it is the institutions to understand their own needs and act according to their infrastructure and resources.
\end{abstract}

Keywords: Big Data Analytics, Educational Industry

\section{INTRODUCTION}

Big data analytics helps the organizations to effectively utilize their data in their business to create opportunities and make smart business moves, results in more efficient operations, more profits, and strong customer base. Significant cost advantages can be acquired by the enterprise when we talk about storage because cloud-based analytics platform takes care of this[1].Big data in the education industry are likely to offer numerous benefits to not only to the educational institutions and also to the students. It also offers more opportunities for the educators to reach out and instruct the students in more effective ways. It will give them an understanding of students' educational experience, and therebyhelp them to evaluate the educational system[2].

Educational bodies such as Schools, Colleges, Universities and others hold very large amounts of data ofstudents and faculty. This data can be analyzed to improve the operational effectiveness of the educational institutions. Big data pave the way for the development of educational needs of the students based on changing educational requirements.

In recent timeslearning pattern has been changing from a conventional instruction delivering methodology to technology enabled learning which includes satellite based distance learning, online learning, MOOC learning, etc. At present most of the Universities are having MOOC courses and online learning portals. Now India, one of the giant knowledge economy in the world have launched National Program in Technology Enhanced Learning (NPTEL) which is having about 90 online courses and more than 10,000 students registered in January 2016. This paper is an attempt to summarize the impact of big data on the educational industry.

\section{IMPACT OF BIG DATA ON EDUCATIONAL INDUSTRY}

A. Improves Student Performance: The main aim of big data within the educational system is to improve the student results. Currently, the only way of evaluating the performance of students is through assignments and exams. However, during his or her learning age, each student hastheir own trial to achieve success. Analyzing this data will help to gain a better understanding of the individual behaviour of students [3]. With big data analytical system, it is possible to monitor student actions, such as:

1. How long they take time to answer a question

2. Which sources they use for exam preparation

3. Which questions do they skip.

4. What type of questionnaire they are eagerly waiting for.

5. What type of thinking ability a particular student is having.

6. What type of solutions necessary to make betterment in the students' performance.

7. Develops best mode of education

8. They can update their learning skills

9. Improves concentration, etc

Customized programs for students can be created and stored online. This is possible with the help of 'blended learning'-a combination of online and offline learning. This gives students the opportunity to follow interested classes and also work at their own place, while still having the possibility for offline guidance by professors.In fact Andrew $\mathrm{Ng}$ class on Machine Learning at Stanford University, 400 students attended but the same course delivered as a MOOC attracted 100,000 students.

B. Effective Mentorship: Big data analytics make it easy for the mentors to identify the ability and weaknesses of individual students and take extra attention and support for them. Mentors can also identify the appropriate teaching practices. They can manage their time effectively to guide the students.Educators can have maximum benefits of big data analytics through the processing of data-driven systems. These can help institutions to create many learning 
experiences according to a student's learning capability and preference[4].

C. Guiding Students to Right Career: If they adopt big data fully into their curriculum,it could be a big help for educators in guiding students for the right careers, That way, students can be better guided to, what to learn and focus, to find success in the job market, andwhat kind of careers best matches their aptitudes and attitudes, andmanymore. This data could also be included in job market data for predicting future needs.Hence, no more blind guesses and assumptions, students could be guided and informed on what jobs might best suit them appropriately.

D. Targeted International Recruiting: With big data in the education system, institutions can more accurately predict applicants and also analyze the possible factors that affect the quantum of applications. Thiswillenable institutions to adapt their recruitment strategies andallocate funds for inservice training to their faculty. Such data will also equip studentsto globally, toanalyze the information about the educational institutions around the world, speedup the search and application process.

E. Holistic Development: With Big Data, Colleges can track their students' performance across the disciplines both at an individual as well as collective level and develop relevant solutions to assist thestudents. Past performance data will help in predicting future performances and institutions can use Big Data analytics to make timely interventions which willadd value to their students' personal development[5].

Bigdata analytics helps in identifying the students' demands and trends, whichwill enable the institutions to develop courses and curricula that meet student needs effectively and attracting greater pool of students that results in lower cost and higher revenues. As almost all academic institutions are facing budgetary pressures, Big Data solutions are not only information discovery platforms, but can also be the cost reduction.

\section{CHALLENGES}

\section{A. Student Acquisition}

Tools that are used for communication have changed from traditional media to social media. Universities and colleges have started using socialmedia for the overall marketing. Acquiring the most talented students is not just enlisting. Even though students do extensive on-line search about the prospective institution before getting enrolled, they discuss and understand the student opinion on the institution through discussion forums and thereby connect with others of similar interest, before actually making any physical contact with the institution. Harvard, The University of California and others are using social media as an advertising tool. There are few prominent factors that drive students towards the educational institutions are, personal factors, academic quality, facility, campus, socialization, financial aid and policies. Research done at the University of New Hampshire shows 96\% students use Facebook, $84 \%$ use YouTube, $20 \%$ use blogs and 14\% use Twitter. Big Data solutions enable better analysis of student's sentimentsand through sentiment analysis of the students, wonders can be brought in the student enrolment process. Big Data solutions therefore serve as insight analysis podium [6].

\section{B. Student Conduct}

Conduct of a student is an indication of how well they perform academically. An early assessment of the student's overall campus life which includes task, social habits, eating and sleeping habits, effectiveness of the tutor and so on, play a very vital role towards a student's conduct. Installation of sensors in the college premises provide an insight of student's academic life by tracking the amount of time they spend in classrooms, library, hostel, cafeteria and so on. IoT technology clubbed with analysis of large data sets provides the desired result.

A student's profile, archival conduct and demographic information provide precise and dependable prognosis. Big Data technologies progressively pay the way for the collection, storage and processing of massive amount of data traversing reasonable amount of time encompassing a large variety of data types and samples. These facts thus make them extensively and ideally suitable to mine and measure varying student characteristics engaged in the learning process. Big Data analytics can be used to identify the risk ofstudents drop outs and increase the student retention rate [7].

\section{Research Optimization}

Research practices play an important role in affirming the credibility of any educational institution. The good quality of the research work also brings grants from government and other agencies thus bringing the institution in to the limelight. For the enablement of good quality research projects, the interested and intuitive faculties, students and the available resources should be brought under a single umbrella. Big Data tools and applications make use of intellectual data which inturn aids research practices and management on both personal and collaborative grounds. Academic social networks such as Academia and Research Gate provide a platform for the reasoning of research work. Collaborative cloud based Big Data analytics provide insights thereby allowing researchers across the globe to find likeminded people who could contribute to the projects. The success or failure of a research work can be determined by using predictive analysis. If early results are unsatisfactory the research can be brought to conclusion and if the results are promising, then an estimation of the research pace and resources can be planned.

Big Data solutions incur much lower cost for the storage and processing of magnitudes of research data, thereby serving as a storage and analytical platform. 


\section{Improving Teaching Efficiency}

The role of teachers havechanged with the emergence of Big Data enhanced education. Enormous amount of educational data generated requires teachers to be more equipped and qualified to work on the analysis process. Teachers are required to master the cutting edge technologies and keep pace with new tools and technologies. Instantaneous feedback helps to determine the student's learning curve, detect student requirements, foresee future performances and enables teachers to make effective changes in the teaching methodologies. Teachers must be quick enough to work on the required entity from the explosive student dataset. The course material level and its effectiveness can be judged by student's sentiments about a particular teacher. This can help the teachers as well as the organizations to take corrective actions. Appreciation and rewards can be conferred to those teachers about whom students exhibit positive sentiments.

\section{CONCLUSION}

Present Technology can do more than just keep the students engaged; it can equip teachers, colleges and policy makers with the insights and analytics that can help them to make better decisions for the students. Big data analytics is used in each and every field and provides valuable information. It lets you do things that were never dreamed of before. Important decisions can be improved in the current scenario and it is possible only if you carry out predictive big data analytics.It has boundless potential to improve quality of higher education and take it to pinnacle in the sub arena of distance education and online education.

\section{REFERENCES}

[1] Wikipedia wesite [Online] Available at: https:// en. Wikipedia .org / wiki / Big_data

[2] Ling Cen, DymitrRuta and Jason Ng, "Big Education: Opportunities for Big Data Analytics", IEEE Conference on Digital Signal Processing (DSP), 2015.

[3] Allerin Website [Online] Available at: https://www. allerin.com/blog / 4- ways - big - data -is - transforming - the- education - sector.

[4] JISC cetis [Online] Available at: http://publications.cetis.org.Uk/wpcontent/uploads/2012/12/Institutional-Readiness-for-Analytics, Vol. 1, No.8.pdf.

[5] M. A. Chatti, A. L. Dyckhoff, U. Schroeder, and H. Thüs, "A Reference Model for Learning Analytics." International Journal of Technology Enhanced Learning, Vol. 4, No. 5, pp. 318-331, 2012.

[6] NourMoahammedAlmadhoun, P. DhanapalDurai Dominic and Lai Fung Woon, "Social Media as a Promotional Tool in Higher Education in Malaysia", IEEE National Postgraduate Conference, 2011.

[7] Robert Stackowiak, VenuMantha and Art Licht, "Improving Higher Education Performance with Big Data", Oracle Enterprise Architecture White Paper, April 2015. 